\title{
Pulmonary veins variations with potential impact in thoracic surgery: a computed-tomography-based atlas
}

\author{
Mateusz Polaczek ${ }^{1,2}$, Pawel Szaro ${ }^{1,3}$, Lilia Jakubowska ${ }^{4}$ Jacek Zych $^{2}$, Jaroslaw Religioni ${ }^{5}$, \\ Tadeusz M. Orlowski ${ }^{5}$
}

${ }^{1}$ Department of Descriptive and Clinical Anatomy, Medical University of Warsaw, Warsaw, Poland; ${ }^{2}$ Third Department of Lung Diseases and Oncology, National Tuberculosis and Lung Diseases Research Institute, Warsaw, Poland; ${ }^{3}$ Department of Radiology, Sahlgrenska University of Gothenburg, Gothenburg, Sweden; ${ }^{4}$ Department of Radiology, ${ }^{5}$ Department of Surgery, National Tuberculosis and Lung Diseases Research Institute, Warsaw, Poland

Contributions: (I) Conception and design: M Polaczek, P Szaro, L Jakubowska, J Zych, J Religioni, TM Orlowski; (II) Administrative support: J Zych, TM Orlowski; (III) Provision of study materials or patients: M Polaczek, P Szaro, L Jakubowska, J Zych, J Religioni; (IV) Collection and assembly of data: M Polaczek, P Szaro, L Jakubowska; (V) Data analysis and interpretation: M Polaczek, P Szaro, TM Orlowski; (VI) Manuscript writing: All authors; (VII) Final approval of manuscript: All authors.

Correspondence to: Mateusz Polaczek, MD. 3rd Department of Lung Diseases, National Tuberculosis and Lung Diseases Research Institute, Plocka 26 Street, 01-138 Warszawa, Poland. Email: polaczek@me.com.

Background: Pulmonary veins (PVs) are important during segmentectomy. Many case reports prove that they may be the source of bleeding during surgery, especially when anatomical variants are present. We decided to describe venous variations and prepare a computed tomography based atlas of our observations.

Methods: The study was conducted using 135 chest computed tomography studies with intra venous iodine contrast injection. The study population contained 86 females and 49 males, mean age was 60 . Thirteen people had atrial fibrillation. Images were analysed using radiological workstation.

Results: The variations were divided into three categories: atypical topography of the PV, atypical venous outflow to the left atrium (LA), atypical venous vascularization of the lung bronchopulmonary segment. Retrobronchial course of the vein of the posterior segment of the right upper lobe was observed in $8.15 \%$. The most common variant of atrial venous outflow was the direct outflow of the middle lobe vein, observed in $25.19 \%$ of cases and the long common trunk of left PVs in $11.11 \%$. The split drainage from the middle lobe into the right superior pulmonary vein (RSPV) and the right inferior pulmonary vein (RIPV) was observed in $9.63 \%$ as the full drainage into the RIPV in $2.96 \%$.

Conclusions: Long common trunk of left PVs and numerous variants of venous vascularisation of the middle lobe are the variations that may pose potential problems during thoracic surgeries. The frequency is high enough to justify the routine assessment of pulmonary vessels with computed tomography before surgery.

Keywords: Pulmonary veins (PVs); anatomy; computed tomography (CT); vascular complications

Submitted Nov 03, 2019. Accepted for publication Jan 08, 2020.

doi: $10.21037 /$ jtd.2020.01.34

View this article at: http://dx.doi.org/10.21037/jtd.2020.01.34

\section{Introduction}

During anatomical lung resections pulmonary veins (PVs) are among the vascular structures in the hilum that need to be ligated (1). PVs play also an important role in determining the lung segmental anatomy. Taking under consideration the rising position of segmentectomy for the treatment of non-small cell lung cancer, this procedure will be performed more and more frequently (2). During segmentectomy, after identifying the lobar branch of PV, 
the dissection should proceed distally and identification of intrasegmental (central) and intersegmental (subsegmental) veins should be carried $(3,4)$. The virtual plane created by intersegmental vein will become the plane of the dissection, this vein itself should remain intact (4). Preoperative assessment of lung vascular and segmental anatomy is important and computed tomography (CT) is a useful method (5).

Atypical vascular anatomy needs to be held in mind during dissection of the hilum, fissures and before ligating any vascular structures. PVs variations contribute to increased number of vascular complications (6), which are reported in more than $2.9 \%$ of cases (7). In previous study we proved that atypical venous anatomy was noticed by surgeon (and problematic in some cases) in more than $3 \%$ of surgeries (8).

The development and widespread of minimally invasive techniques like video-assisted thoracic surgery (VATS) resulted in better outcomes of patients (2). Nevertheless, the limited vision that is characteristic for thoracoscopic resections, causes difficulties with identification of smaller vascular structures, therefor preoperative assessment of vessels using CT provides useful information for surgeons $(9,10)$. Number of cases were reported, in which identification of anatomical variation of a PV helped to avoid potential complications (10-12).

Thus we aimed to investigate the variations of $\mathrm{PVs}$ and to indicate the ones that may impact the course of thoracic surgery, with the use of computed tomography, in unselected population of patients.

\section{Methods}

The study was based on retrospective analysis of 135 chest computed tomography examinations with iodine contrast enhancement performed in our institution between 2011 and 2017. The clinical indication for CT was one of the following: unspecific changes in chest radiogram, history of haemoptysis, suspicion of pulmonary embolism and followup of peripheral pulmonary nodules of less than $10 \mathrm{~nm}$ in diameter; all the radiological reports stated no significant abnormalities, so the study population can be considered representative for the general population of patients. Study population was aged 18-84 (average age was 59.97), there were 86 females and 49 males. The main inclusion criterion was good contrast enhancement of PVs defined as the density over 80 Hounsfield Units (HU) of the region of interest (ROI) in the right inferior pulmonary vein (RIPV) trunk. The average ROI density was $266.11 \mathrm{HU}$. The exclusion criteria contained all clinical conditions impacting pulmonary circulation and were described in details in the study protocol. The only exception involved patients with $\mathrm{AF}$, who were included in this stud. There were 13 cases of AF included.

Examinations were performed using Sensation 16 (SIEMENS AG, Germany) 16-row scanner and Revolution GSI (GE Healthcare, USA) 64-row scanner. The reconstructions were made with 1.00 and $1.25 \mathrm{~mm}$ thick layers. Iodine intra-venous contrast was injected into cephalic vein using automatic syringe.

After selection of 135 studies from the database the DICOM files were imported from a PACS server to Syngo. via - syngo.via Client 3.0 (SIEMENS Healthcare GmbH, Germany) workstation and processed in syngo.CT Vascular Analysis (SIEMENS Healthcare GmbH, Germany) work mode. The source material in axial planes was reconstructed into sagittal and coronal planes using multi-planar reformations (MPR). MPR was also used to reconstruct oblique planes. PVs were identified and presented using curved-planar reformations (CPR). Volume rendering technique (VRT) was used to create three-dimensional (3D) color-coded images, automatic and manual segmentation techniques were used to brush all structures covering PVs.

At the beginning great vessels were evaluated for any malformations. The left atrium (LA) and all PVs were identified and the course of all PV with direct outflow to LA were tracked distally up to at least two divisions. A 3D VRT models were created and used as navigation. PVs were identified as segmental branches based on the segmental bronchial anatomy. For intersegmental veins the dominant drainage segment was determined if possible.

All observations were saved as images in TIFF format and written to the study form. Numerical analysis was performed using Excel worksheet (Microsoft). Data is presented as number of cases and frequency. Most numbers were presented with two decimal places.

The Institutional Ethics Committee was informed about the study and the Committee stated no need for its approval. All the patients signed informed consent for their medical data to be used for scientific purposes.

\section{Results}

The commonly observed segmental venous vascularisation is shown in Figure S1. The drainage of right upper lobe contained three main segmental veins creating superior 
lobar vein, which continues as right superior lobar vein. The vein of the posterior segment of the right upper lobe (V2R) runs dorsally in proximity to the oblique fissure to eventually turn medially and connect with the common trunk of the apical (V1R) and anterior segment of the right upper lobe (V3R). The middle lobe is drained by two separate veins that form common trunk before the merge with right superior lobar vein to create the right superior pulmonary vein (RSPV). The apical segment of the lover lobe is drained with two to three veins that merge into one common trunk-the vein of the apical segment of the right lower lobe (V6R), although small accessory veins with independent outflow for this segment are often present. The basal segments are drained by three to four segmental veins, the most proximal to the LA is the vein of the medial basal segment of the right lower lobe (V7R), which defines the formation of the common basal root, and is localised medially, close to the pulmonary ligament. The RIPV is created by common basal root and V6R. The trunk of RIPV is very short and sometimes only visible intrapericardially. RSPV and RIPV inflow into the LA separately and the ostia can be well defined.

Typically, segmental veins draining apical and posterior segment of the left upper lobe created left apicoposterior vein $(\mathrm{V} 1+2 \mathrm{~L})$, which receives the vein of the anterior segment of the left upper lobe (V3L). On the anterior surface of the left main bronchus left superior lobar vein merges with the trunk from the lingual segments $(\mathrm{V} 4+5 \mathrm{~L})$ or with two separate veins from the lingual segments-V4L and V5L to form left superior pulmonary vein (LSPV). The left common basal root is created by three segmental veins. Posterior to the left inferior lobar bronchus left common basal root merges with the vein of the apical segment of the left lower lobe (V6L) to form the left inferior pulmonary vein (LIPV), which runs in the posterior aspect of left pulmonary ligament. LSPV and LIPV inflow into the LA separately and the ostia can be defined.

This typical pattern was observed only in $37 / 135$ cases (27\% of cases).

Venous vascularization of each bronchopulmonary segment was not consistent in the study population. Although identification of greater vessels-intersegmental and subsegmental veins was possible, some accessory veins were often encountered and hard to classify. This would complicate the numerical data. Thus only different patterns of segmental venous vascularization are presented throughout Figures S2-S6 in the Supplementary file.

All identified variations considered as surgically important or troublesome were divided into one of three categories: atypical topography of the PV, atypical venous outflow to the LA, atypical venous vascularization of lung bronchopulmonary segment. All the variations with the occurrence are summarized in Table 1.

Among atypical topography of the PV, 27 (out of 135) cases were classified into seven different categories. The most common variation observed in $8 \%$ of cases was retrobronchial course of $\mathrm{V} 2 \mathrm{R}$, in which $\mathrm{V} 2 \mathrm{R}$ runs posterior to the intermediate or inferior lobar bronchus on the right, passing vertically and emptying into RSPV, RIPV or directly into LA (Figure 1). Retrobronchial course of V1R is a very similar variation (Figure 2), as is one case of the vein of the posterior segment of the upper left lobe (V2L), running posteriorly and crossing the left inferior lobar bronchus (Figure S7). Three variation types where the vein runs medially, close to the mediastinum and superficial to the mediastinal pleura were observed: the trunk of the LIPV runs in proximity to thoracic aorta, also V1R and V2R run medially and anteriorly or posteriorly to the right pulmonary artery and crossing it at the right hilum (Figures 1,3). Also two cases of the vein of the apical segment of the left upper lobe (V1L) were observed as they crossed anteriorly the left pulmonary artery medial to the first arterial branch at the left hilum.

Atypical venous outflow to LA was the most commonly observed category of variation of PVs, altogether 60 different cases were observed and categorised into six different types. The most important is a separate vein draining the middle lobe (as a single or one of multiple vessels) and directly emptying to LA. Also we observed V1R or V2R emptying on the roof of LA. V6R could also have a separate inflow into LA. A very important variation observed in $11 \%$ of cases was the long common trunk of left PVs, defined as a trunk over $10 \mathrm{~mm}$ long (Figure 4). Common trunk of right PVs was observed only in one case (Figure 5). Also one case represented very strange variation where five separate veins emptied to LA on the right, but it was a patient with atrial fibrillation.

Third main category of variations contains all the atypical venous vascularization of lung bronchopulmonary segments. Thirty-eight cases were categorised into 8 different categories. The biggest category contained all the cases of split drainage from the middle lobe. Normally the middle lobe is drained by two veins, one of the medial and one of the lateral segment (V5R and V4R respectively), which create a common trunk or less commonly separately outflow into RSPV. The split drainage contains mostly cases when 
Table 1 Different variations of pulmonary veins $(\mathrm{N}=135)$

\begin{tabular}{|c|c|c|c|}
\hline Variation group & Variation type & Number of cases observed & Frequency observed (\%) \\
\hline \multirow{5}{*}{$\begin{array}{l}\text { Atypical topography of the } \\
\text { pulmonary vein }\end{array}$} & Retrobronchial course of V6R & 6 & 4.44 \\
\hline & V2R running medially & 1 & $<1$ \\
\hline & V1R runs medially in proximity to SVC & 3 & 2.22 \\
\hline & V1L crosses LPA proximally to its first branch & 2 & $<2$ \\
\hline & Retrobronchial course of V2L & 1 & $<1$ \\
\hline \multirow{4}{*}{$\begin{array}{l}\text { Atypical venous outflow to } \\
\text { the left atrium }\end{array}$} & Direct outflow of the middle lobe vein & 34 & 25.19 \\
\hline & Outflow of V1R or V2R on the atrial roof & 4 & 2.96 \\
\hline & Long common trunk of left pulmonary veins & 15 & 11.11 \\
\hline & Five separate veins emptying to LA on the right side & 1 & $<1$ \\
\hline \multirow{6}{*}{$\begin{array}{l}\text { Atypical venous } \\
\text { vascularization of } \\
\text { pulmonary segments }\end{array}$} & Split drainage from the middle lobe & 13 & 9.63 \\
\hline & Drainage from the middle lobe to RIPV & 4 & 2.96 \\
\hline & V2R drains into RIPV & 9 & 6.67 \\
\hline & V6R drains into RSPV & 1 & $<1$ \\
\hline & Partial outflow from the lingua of the left lung to LIPV & 5 & 3.70 \\
\hline & V2L drains to LIPV & 2 & $<2$ \\
\hline
\end{tabular}

$\mathrm{N}$, number of cases; V2R, vein to the posterior segment of the right upper lobe; V6R, vein to the apical segment of the right lower lobe; V1R, vein to the superior segment of the right upper lobe; SVC, superior vena cava; LIPV, right inferior pulmonary vein; V1L, vein to the superior segment of the left upper lobe; LPA, left pulmonary artery; V2L, vein to the posterior segment of the left upper lobe; RIPV, right inferior pulmonary vein; RSPV, right superior pulmonary vein.

there is a middle lobe vein opening to LA but part of the drainage remains to RSPV. Less commonly, there is the split drainage from the middle lobe to RIPV and RSPV. Possible variations of the middle lobe split drainage are summarised by examples in Figure 6 and continued in Figure 7. Different subtypes of atypical segmental vascularisation contained drainage of the middle lobe vein to RIPV (Figure 8), V2R emptying into RIPV, V6R emptying into RSPV (Figure S8) and on the left outflow of V2L into LIPV (Figure 3) and partial drainage of lingual segment into LIPV (Figure S9). Venous vascularisation of lower lobes was more homogenous, nevertheless two cases of missing segmental vein of the right anterior basal segment (V8R) were observed, in which cases drainage from the region of the anterior basal segment of the right lower lobe was conducted by V9R and V5R.

\section{Discussion}

The course of intersegmental branches of PVs is important in modern thoracic surgery because it determines the surgical borders of bronchopulmonary segments $(4,5)$. Among atypical topography of the PV, retrobronchial course of V2R is the most common, V6R can be found in the very same location, posterior to the intermediate bronchus. This variation was described by Matsubara et al. who emphasized its importance during oesophagostomy with lymphadenectomy of subcarinal lymph nodes, this vessel could be the potential source of major bleeding (13). It is worth mentioning that 'symmetrical' variation of 

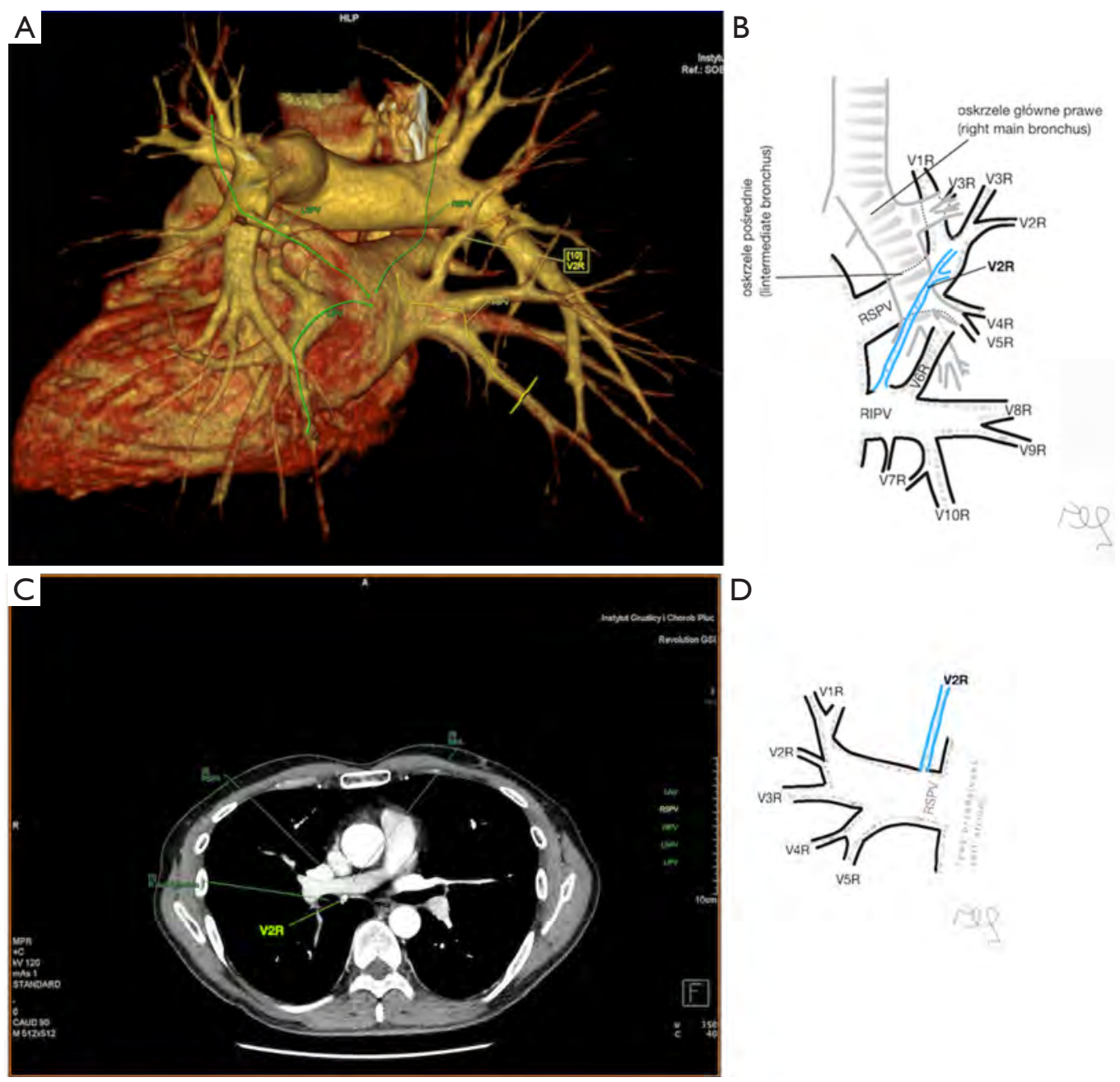

Figure 1 Variant topography of the vein of the posterior segment of the right upper lobe (V2R). V2R runs posteriorly to the intermediate bronchus and empties into the trunk of the right inferior pulmonary vein (RIPV): (A) CT with VRT, posterior view; (B) schematic posterior left oblique view. V2R runs medially to the intermediate bronchus and crosses posteriorly the trunk of the right pulmonary artery; (C) CT, axial plane, mediastinal window; (D) schematic anterior view. CT, computed tomography; VRT, volume rendering technique.

retrobronchial course of $\mathrm{V} 2 \mathrm{~L}$ was not described in the literature up to date. On the other hand, the variation of medial course of $\mathrm{V} 1 \mathrm{R}$ with proximity to superior vena cava was once described by Marom et al. (14).

Common venous trunk of left PVs was observed in $17.8 \%$ of cases and is much more common than commRPV. In the literature commLPV was observed in $6-33 \%$ of cases (14-19), and by some authors is considered as the most common variant of atypical venous outflow to LA (19). The difficulties that may be related to a long trunk of commLPV need to be emphasised, that is based on the literature reports of vascular complications (6), this variation is considered as the most troublesome and needs to be diagnosed before surgery.

Variants with direct outflow of accessory veins to LA from the right lung: the middle lobe vein in $25 \%$ of cases and smaller PVs in approx. $6.70 \%$, is also important and vividly discussed in the literature. Especially meaningful are the veins emptying on the atrial roof (V1R or V2R) (20) and direct outflow of V6R, which sometimes may be located very high on the medial atrial wall, in proximity to RSPV (21). Those variant are of special interest for interventional cardiologists, not only it may impact the isolation of PVs during ablation procedures, but also PV outflow anatomy may be a risk factor for atrial fibrillation itself, which was suggested in our earlier research, where detailed ostial 

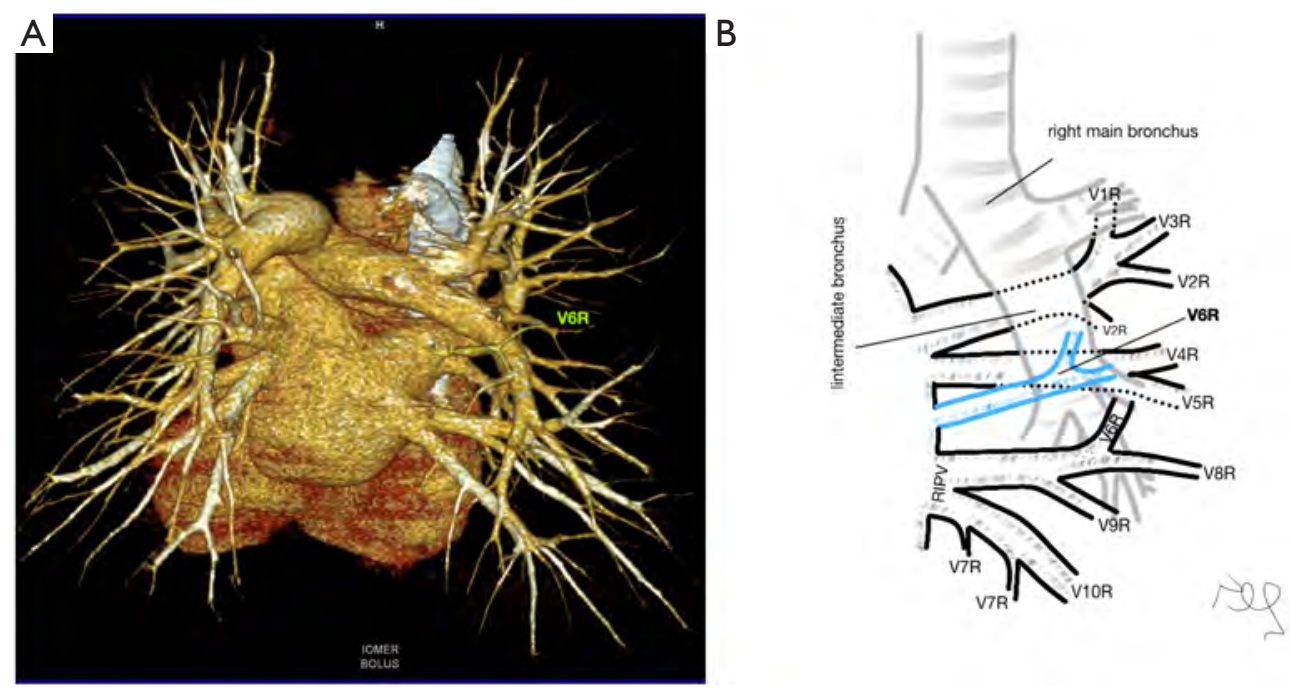

Figure 2 The vein of the apical segment of the right lower lobe (V6R), runs posteriorly to the intermediate bronchus and outflows directly to the left atrium. (A) CT with VRT, posterior view; (B) schematic posterior left oblique view. CT, computed tomography; VRT, volume rendering technique.
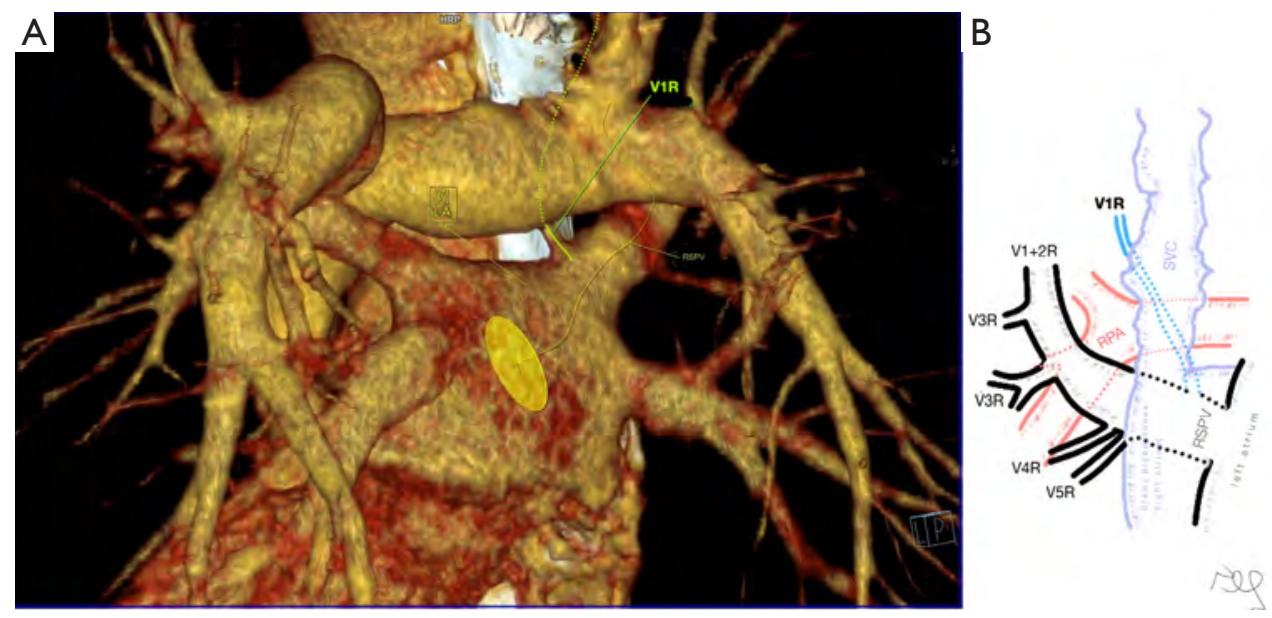

Figure 3 The vein of the superior segment of the upper right lobe (V1R) runs medially and places between the superior vena cava (SVC) and the right pulmonary artery (RPA). (A) CT with VRT, left posterior oblique view; (B) schematic representation of V1R with relation to RPA, SVC, anterior view; CT, computed tomography; VRT, volume rendering technique.

anatomy was investigated (22).

Among atypical venous vascularization of bronchopulmonary segments variants, the most important and common are related to the middle lobe. In our material split drainage was observed in $10 \%$ of cases, the full drainage to RIPV was found in about $3 \%$ of cases. There is lack of statistical data in the literature to prove our observation, nevertheless there is a multitude of case report of drainage into RIPV (mostly split drainage, V4R running into RIPV) $(10,23-25)$. In one series of 30 cases in $3 \%$ full drainage of the middle lobe vein to RIPV was observed (26). It is worth mentioning, that because of the short trunk of RIPV, before its ligation during right inferior lobectomy, it needs to be dissected distally, so the middle lobe vein gets exposed and the venous outflow from the middle lobe can be preserved $(25,27)$. The split drainage from the lingua of the left upper lobe is much less frequent. The potential importance of this variation was described by Akiba et al., who identified it presurgically with CT (28). Full drainage from the lingual segments to LIPV was not found in our 


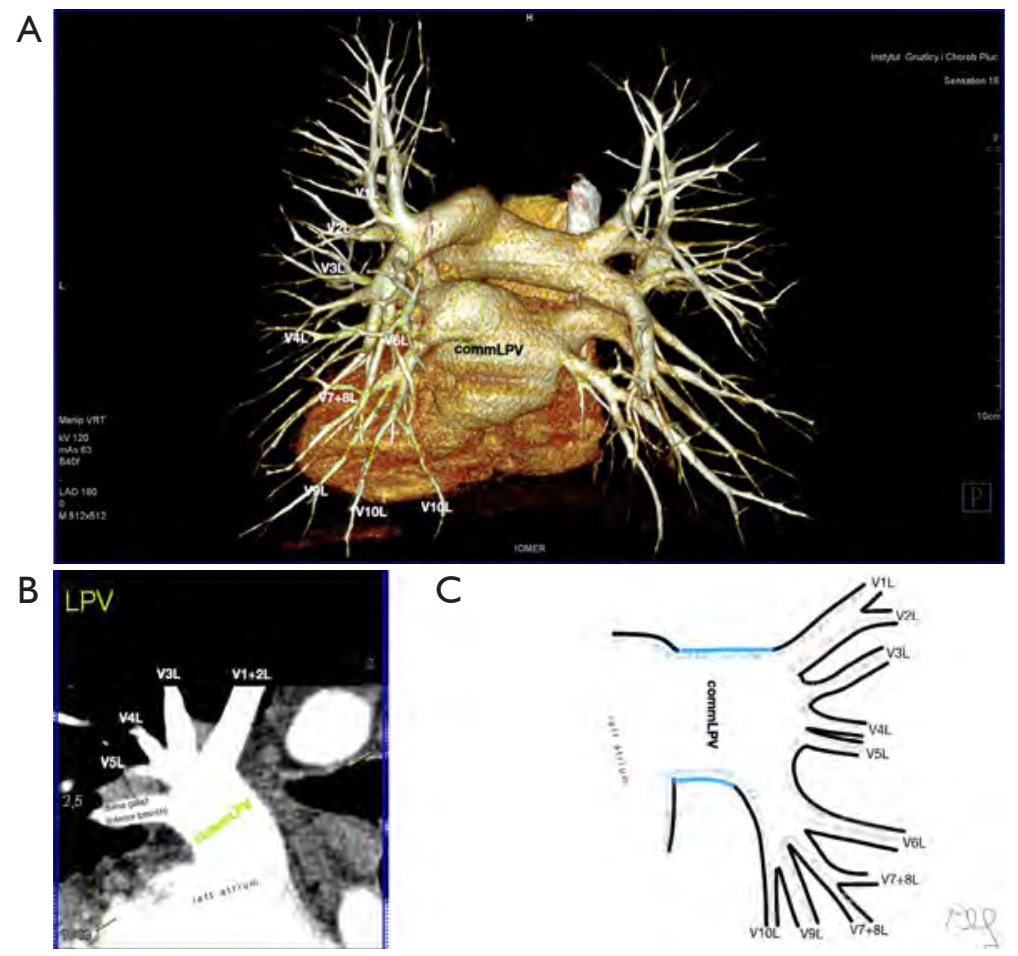

Figure 4 Common trunk of left pulmonary veins (commLPV) composed of multiple branches to the upper lobe segments and lower lobe trunk. (A) CT with VRT, posterior view; (B) CT with CPR; (C) schematic anterior view. CT, computed tomography; VRT, volume rendering technique; $\mathrm{CPR}$, curved planar reformations.
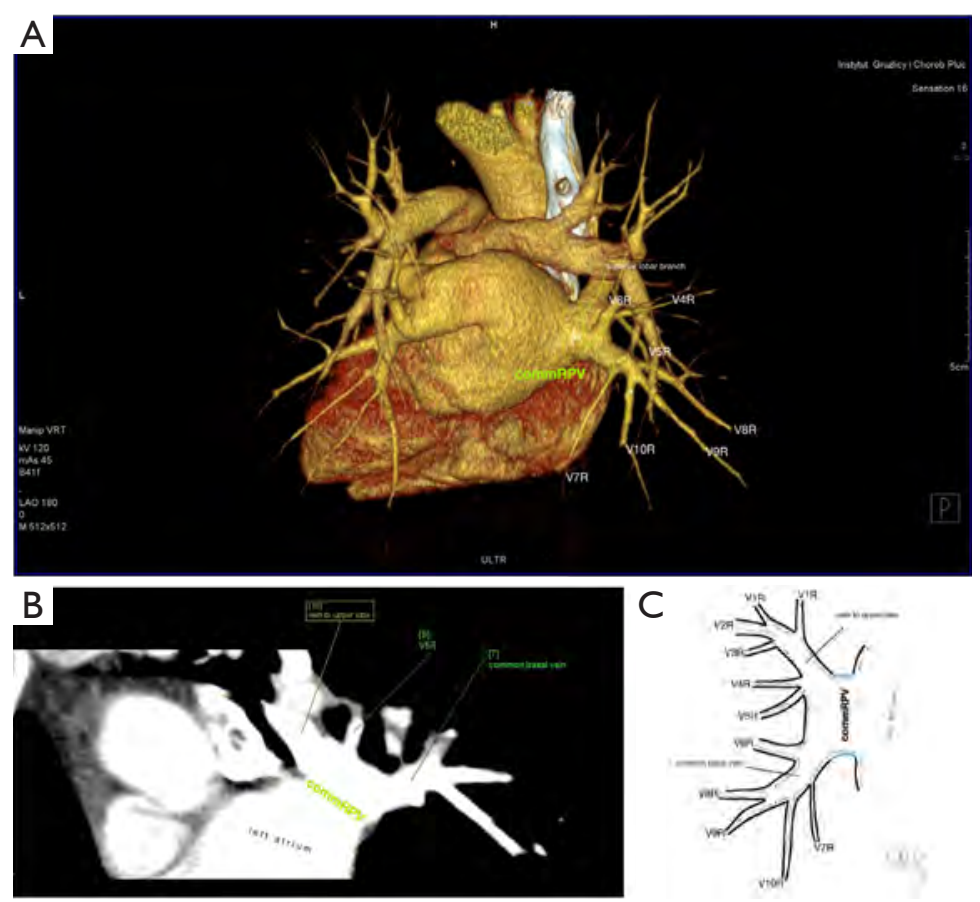

Figure 5 Common trunk of right pulmonary veins (commRPV) composed of two short branches. (A) CT with VRT, posterior view; (B) CT with CPR; (C) schematic anterior view. CT, computed tomography; VRT, volume rendering technique; CPR, curved planar reformations. 

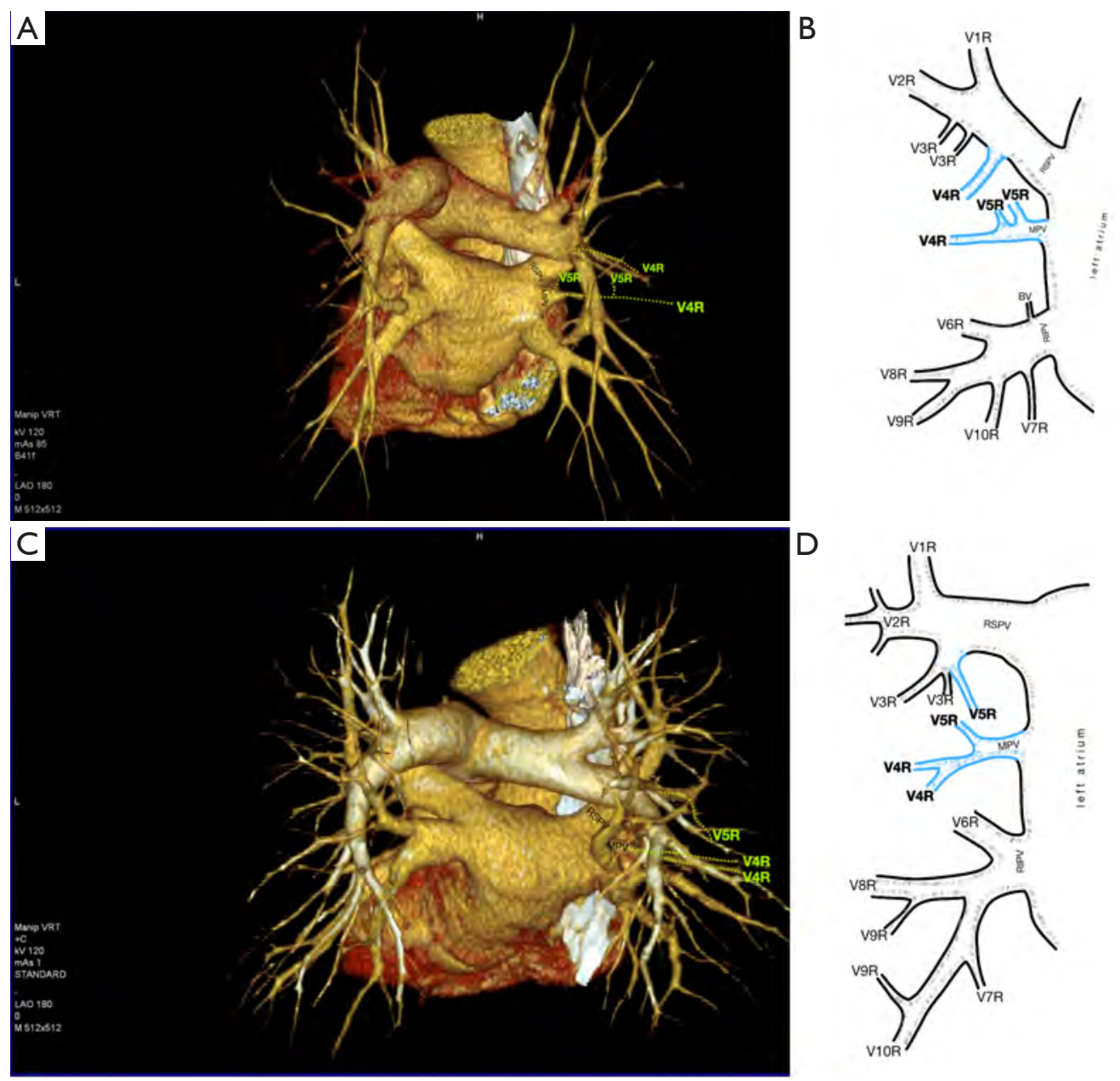

Figure 6 Split drainage from the middle lobe. Direct outflow of the middle lobe vein (MPV) to the left atrium (LA) and accessory vein from the lateral segment of the middle lobe (V4R) running into the right superior pulmonary vein (RSPV): (A) CT with VRT, posterior view; (B) schematic anterior view. Direct outflow of MPV to LA and accessory vein from the medial segment of the middle lobe (V5R) running into the vein of the anterior segment of the upper right lobe (V3R): (C) CT with VRT, posterior view; (D) schematic anterior view. CT, computed tomography; VRT, volume rendering technique.

material, in the literature there are only two reports of this extremely rare variation $(10,14)$.

An interesting variation is the drainage of accessory V6R vein to RSPV, we found only one case, but previous studies suggested it might be as frequent as $22 \%(17)$.

In an analysis of 3,076 VATS cases Decaluwe et al. reported vascular complications frequency of $2.9 \%$ and the majority of cases needed conversion to open thoracotomy. Most of these complications were related to misinterpreting the vascular structures (veins) and most reported cases considered the middle lobe veins and the lingual veins (7). Moreover, as previously stated, in a retrospective analysis, we reported $3.12 \%$ of unclear venous anatomy revealed during lobectomy (8). It can be assumed that the variations of segmental vascularisation, venous topography and venous outflow are of great importance. Thereafter routine identification of venous structures in computed tomography prior to thoracic surgery may be beneficial and may decrees number of vascular complications, especially when minimally invasive techniques are in use.

Due to very specific anatomy of bronchopulmonary segment, with the vein running at the periphery as intersegmental or subsegmental vein, and only some smaller vessels which run centrally, we found it very inaccurate to demonstrate detailed vascularisation for each segment (17). Although we believe it is very important to emphasize the 


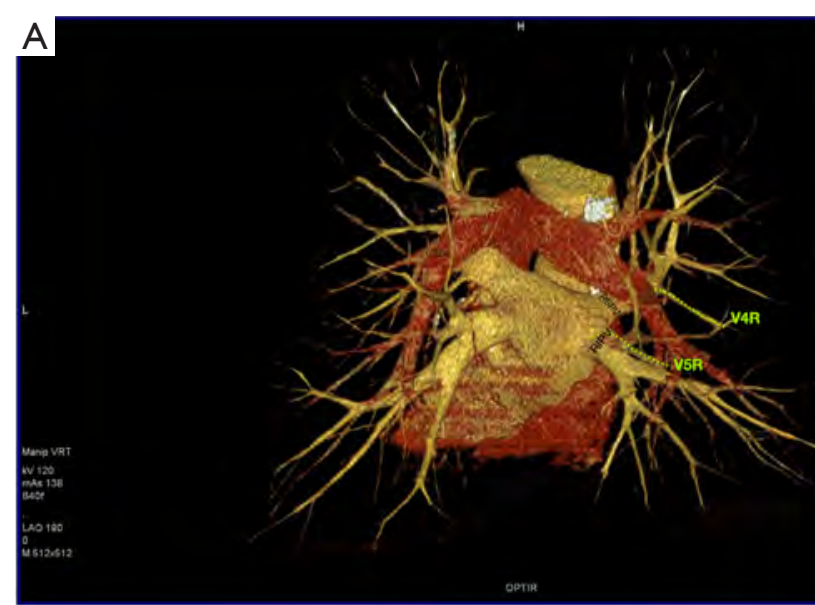

B
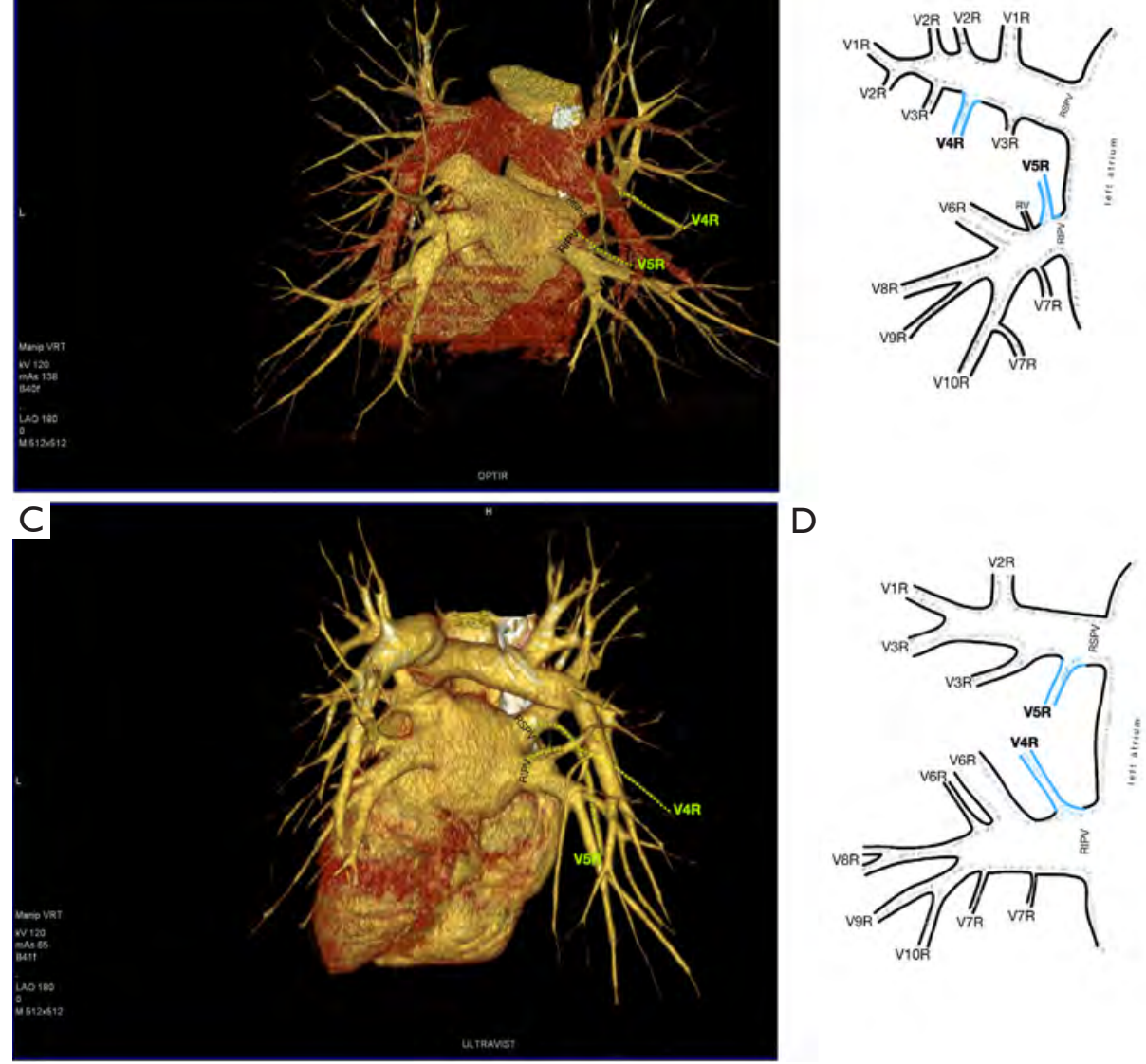

Figure 7 Split drainage from the middle lobe. V4R flows into RSPV and V5R flows into the right inferior pulmonary veins (RIPV): (A) CT with VRT, posterior view; (B) schematic anterior view. V5R runs into RSPV and V4R outflows into RIPV: (C) CT with VRT, posterior view; (D) schematic anterior view. RSPV, right superior pulmonary vein; CT, computed tomography; VRT, volume rendering technique.

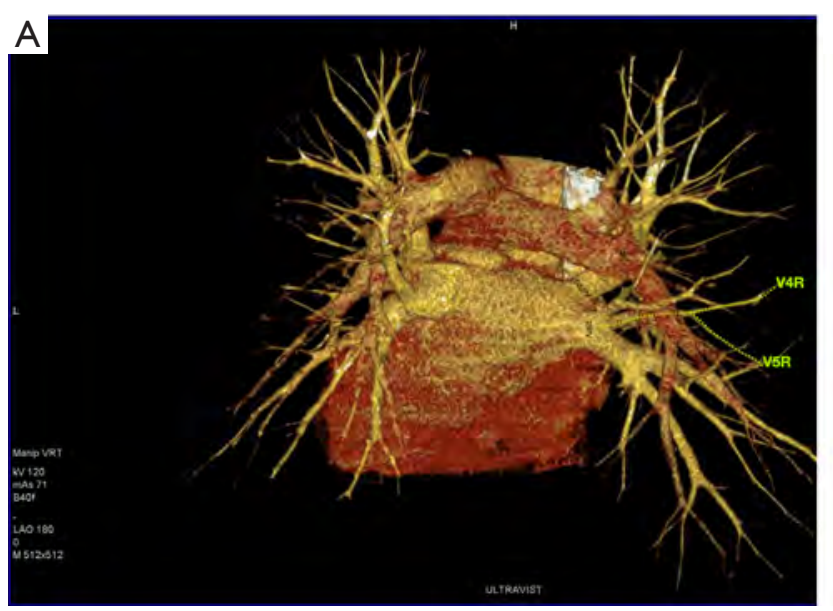

B

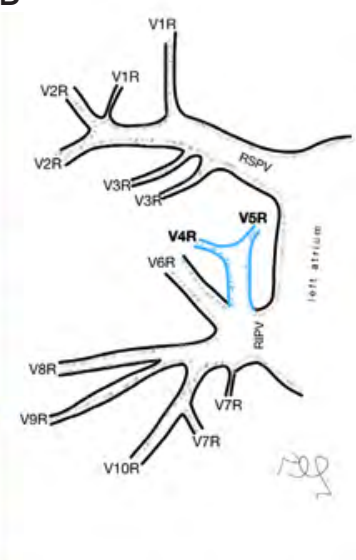

Figure 8 Full drainage of the middle lobe to the right inferior pulmonary vein. (A) CT with VRT, posterior view; (B) schematic anterior view. CT, computed tomography; VRT, volume rendering technique. 
anatomical variations of the proximal part of the PVs, which as shown above impact the surgery, more distant part of the veins should be used mainly as landmarks during the surgery to create the intersegmental planes for segmentectomies (3). Considering our experience we think that precise demonstration of segmental origin for each vein is impossible with computed tomography.

The main limitation of current study is that there was no surgical verification of anatomical variations exposed using CT. Further investigation with detailed presurgical planning and $3 \mathrm{D}$ printing of the pulmonary vasculature to assess the true impact on the complication rate is needed.

The typical pattern for PVs is met in less than one third of cases. The variations we describe and show in our CT-based atlas help to identify and understand potential discoveries clinicians will encounter in daily clinical practice.

\section{Acknowledgments}

Funding: None.

\section{Footnote}

Conflicts of Interest: The authors have no conflicts of interest to declare.

Ethical Statement: The authors are accountable for all aspects of the work in ensuring that questions related to the accuracy or integrity of any part of the work are appropriately investigated and resolved. The Institutional Ethics Committee was informed about the study and the Committee stated no need for its approval. All the patients signed informed consent for their medical data to be used for scientific purposes.

Open Access Statement: This is an Open Access article distributed in accordance with the Creative Commons Attribution-NonCommercial-NoDerivs 4.0 International License (CC BY-NC-ND 4.0), which permits the noncommercial replication and distribution of the article with the strict proviso that no changes or edits are made and the original work is properly cited (including links to both the formal publication through the relevant DOI and the license). See: https://creativecommons.org/licenses/by-nc-nd/4.0/.

\section{References}

1. Pearson FG, Cooper JD, Deslauriers J, et al. editors.
Troracic Surgery. Second Edition. Philadelphia, Pensylvania: Churchill Livingstone, 2002:981-90.

2. Gonzalez-Rivas D, Yang Y, Ng C. Advances in Uniportal Video-Assisted Thoracoscopic Surgery. Thorac Surg Clin 2016;26:187-201.

3. Oizumi H, Kato H, Endoh M, et al. Techniques to define segmental anatomy during segmentectomy. Ann Cardiothorac Surg 2014;3:170.

4. Swanson SJ. Segmentectomy for Lung Cancer. Semin Thorac Cardiovasc Surg 2010;22:244-9.

5. Iwano S, Yokoi K, Taniguchi T, et al. Planning of segmentectomy using three-dimensional computed tomography angiography with a virtual safety margin: Technique and initial experience. Lung Cancer 2013;81:410-5.

6. Nakamura T, Koide M, Nakamura H, et al. The Common Trunk of the Left Pulmonary Vein Injured Incidentally During Lung Cancer Surgery. Ann Thorac Surg 2009;87:954-5.

7. Decaluwe H, Petersen RH, Hansen H, et al. Major intraoperative complications during video-assisted thoracoscopic anatomical lung resections: an intention-totreat analysis. Eur J Cardiothorac Surg 2015;48:588-99.

8. Polaczek M, Religioni J, Orlowski T. Anatomic variations of pulmonary vessels relevant with regard to lung tissue resections - literature review and personal experiences. Kardiochirurgia Torakochirurgia Pol 2013;10:232-8.

9. Akiba T, Marushima H, Harada J, et al. Importance of preoperative imaging with 64-row three-dimensional multidetector computed tomography for safer videoassisted thoracic surgery in lung cancer. Surg Today 2009;39:844-7.

10. Yamada S, Suga A, Inoue Y, et al. Importance of preoperative assessment of pulmonary venous anomaly for safe video-assisted lobectomy. Interact Cardiovasc Thorac Surg 2010;10:851-4.

11. Villa M, Sarkaria IS. Great Vessel Injury in Thoracic Surgery. Thorac Surg Clin 2015;25:261-78.

12. Akiba T, Marushima H, Kamiya N, et al. Thoracoscopic Lobectomy for Treating Cancer in a Patient with an Unusual Vein Anomaly. Ann Thorac Cardiovasc Surg 2011;17:501-3.

13. Matsubara T. Rare but dangerous anomaly of the right pulmonary vein in subcarinal dissection. Ann Thorac Surg 2003;75:1026.

14. Marom EM, Herndon JE, Kim YH, et al. Variations in Pulmonary Venous Drainage to the Left Atrium: Implications for Radiofrequency Ablation. Radiology 
2004;230:824-9.

15. Schwartzman D, Lacomis J, Wigginton WG. Characterization of left atrium and distal pulmonary vein morphology using multidimensional computed tomography. J Am Coll Cardiol 2003;41:1349-57.

16. Kato R. Pulmonary Vein Anatomy in Patients Undergoing Catheter Ablation of Atrial Fibrillation: Lessons Learned by Use of Magnetic Resonance Imaging. Circulation 2003;107:2004-10.

17. Maciejewski R. Atlas of the broncho-vascular ramifications of the lung. Lublin: "Delfin" Publishers, 1995.

18. Kaseno K, Tada H, Koyama K, et al. Prevalence and Characterization of Pulmonary Vein Variants in Patients With Atrial Fibrillation Determined Using 3-Dimensional Computed Tomography. Am J Cardiol 2008;101:1638-42.

19. Sohns C, Sohns JM, Bergau L, et al. Pulmonary vein anatomy predicts freedom from atrial fibrillation using remote magnetic navigation for circumferential pulmonary vein ablation. Europace 2013;15:1136-42.

20. Arslan G, Dincer E, Kabaalioglu A, et al. Right top pulmonary vein: Evaluation with 64 section multidetector computed tomography. Eur J Radiol 2008;67:300-3.

21. Akiba T, Tabei I, Kinoshita S, et al. Three-dimensional computed tomography for lung cancer in a patient with three right vein ostia. Gen Thorac Cardiovasc Surg 2011;59:376-9.

Cite this article as: Polaczek M, Szaro P, Jakubowska L, Zych J, Religioni J, Orlowski TM. Pulmonary veins variations with potential impact in thoracic surgery: a computed-tomographybased atlas. J Thorac Dis 2020;12(3):383-393. doi: 10.21037/ jtd.2020.01.34
22. Polaczek M, Szaro P, Baranska I, et al. Morphology and morphometry of pulmonary veins and the left atrium in multi-slice computed tomography. Surg Radiol Anat 2019;41:721-30.

23. Akiba T, Marushima H, Harada J, et al. Anomalous pulmonary vein detected using three-dimensional computed tomography in a patient with lung cancer undergoing thoracoscopic lobectomy. Gen Thorac Cardiovasc Surg 2008;56:413-6.

24. Wannasopha Y, Oilmungmool N, Euathrongchit J. Anatomical variations of pulmonary venous drainage in Thai people: multidetector CT study. Biomed Imaging Interv J 2012;8:e4.

25. Sugimoto S, Izumiyama O, Yamashita A, et al. Anatomy of inferior pulmonary vein should be clarified in lower lobectomy. Ann Thorac Surg 1998;66:1799-800.

26. Yazar F, Ozdogmus O, Tuccar E, et al. Drainage patterns of middle lobe vein of right lung: an anatomical study. Eur J Cardiothorac Surg 2002;22:717-20.

27. Nattel S. New ideas about atrial fibrillation 50 years on. Nature 2002;415:219-26.

28. Akiba T, Marushima H, Odaka M, et al. Pulmonary vein analysis using three-dimensional computed tomography angiography for thoracic surgery. Gen Thorac Cardiovasc Surg 2010;58:331-5. 

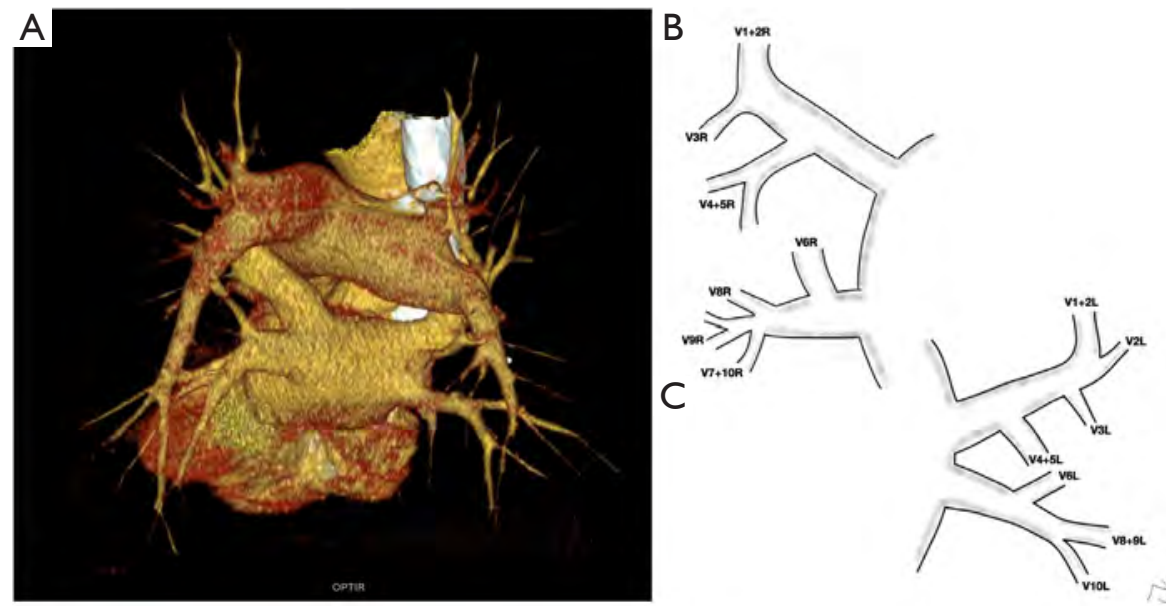

Figure S1 Normal variant of the segmental vascularisation of the lungs. (A) CT with VRT, posterior view; (B) right pulmonary veins; (C) left pulmonary veins. CT, computed tomography; VRT, volume rendering technique.

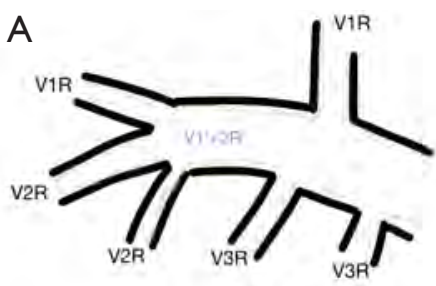

C

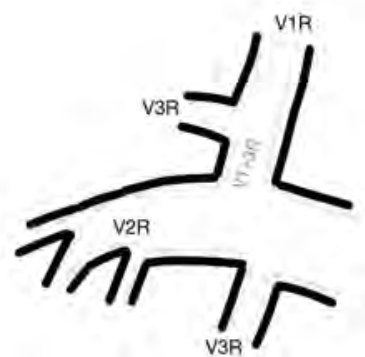

B

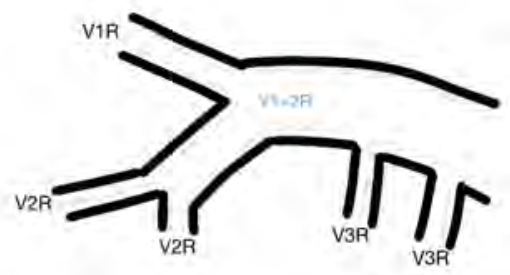

D

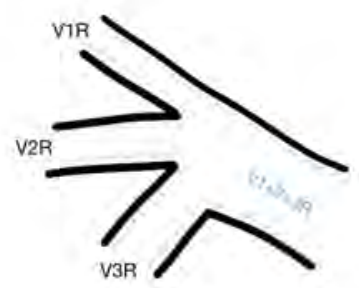

Figure S2 Most common segmental veins of the right upper lobe. 
A

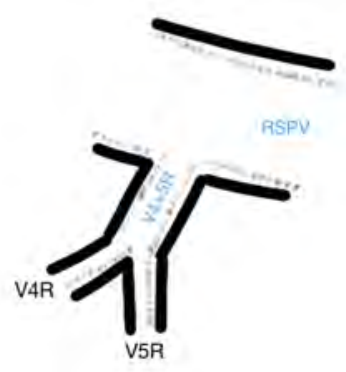

C

$\mathrm{E}$

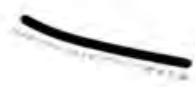

ASPV

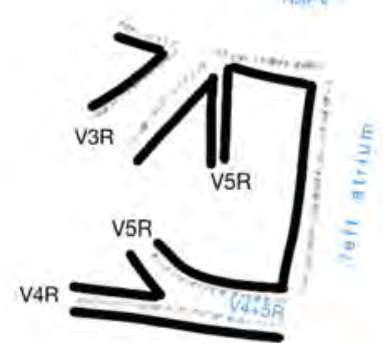

$\mathrm{F}$
B
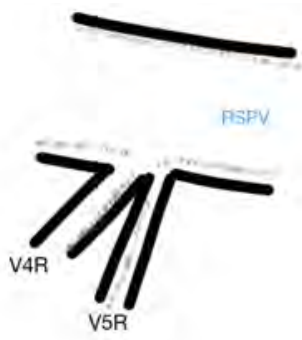

D
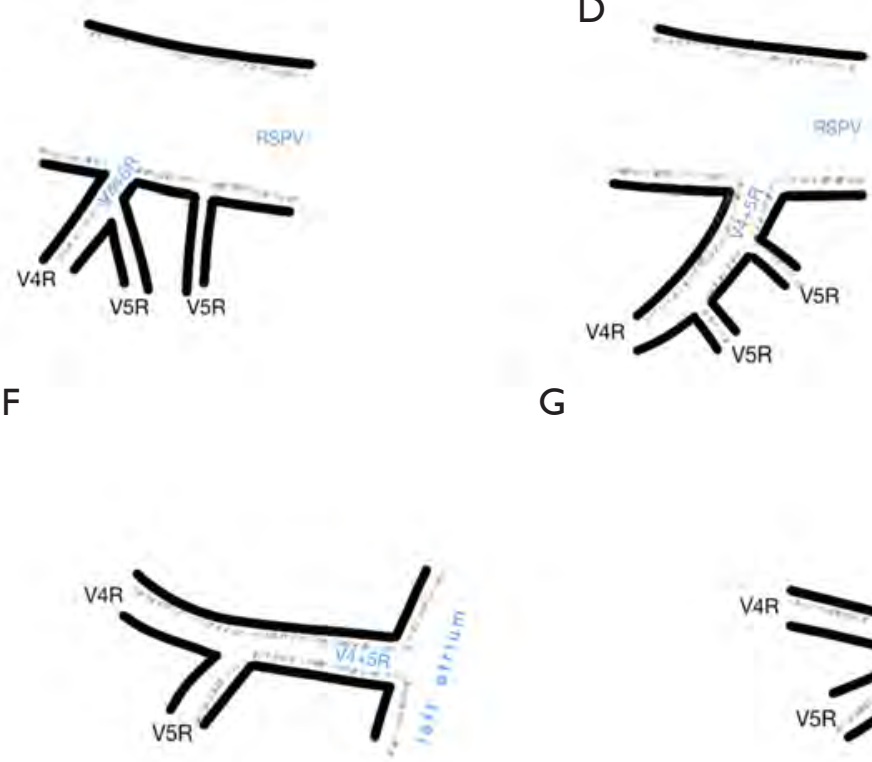

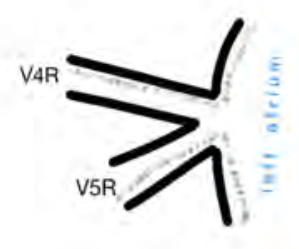

Figure S3 Most common segmental veins of the middle lobe. RSPV, right superior pulmonary vein. 

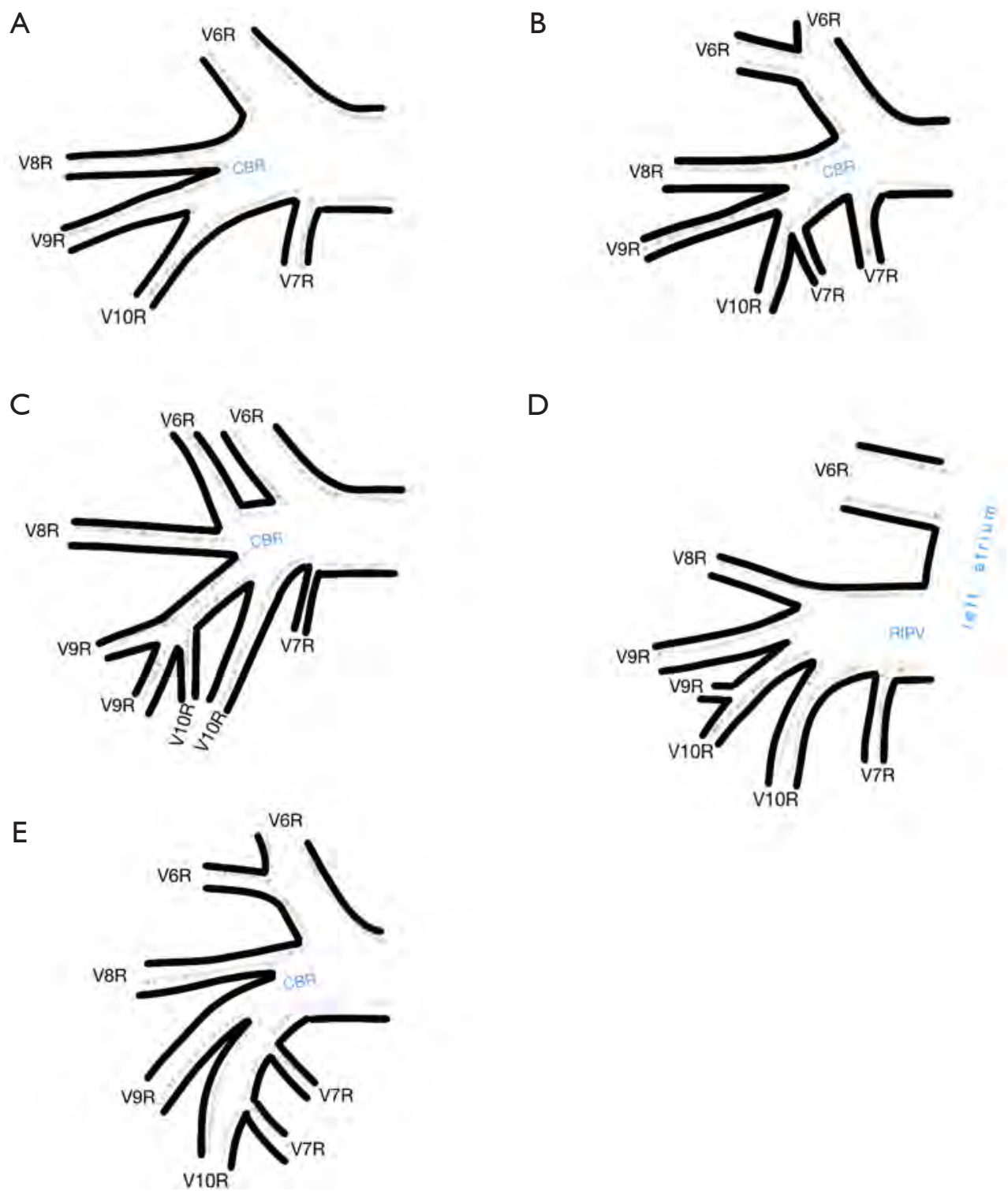

Figure S4 Most common segmental veins of the right lower lobe. CBR, common basal root; RIPV, right inferior pulmonary vein. 

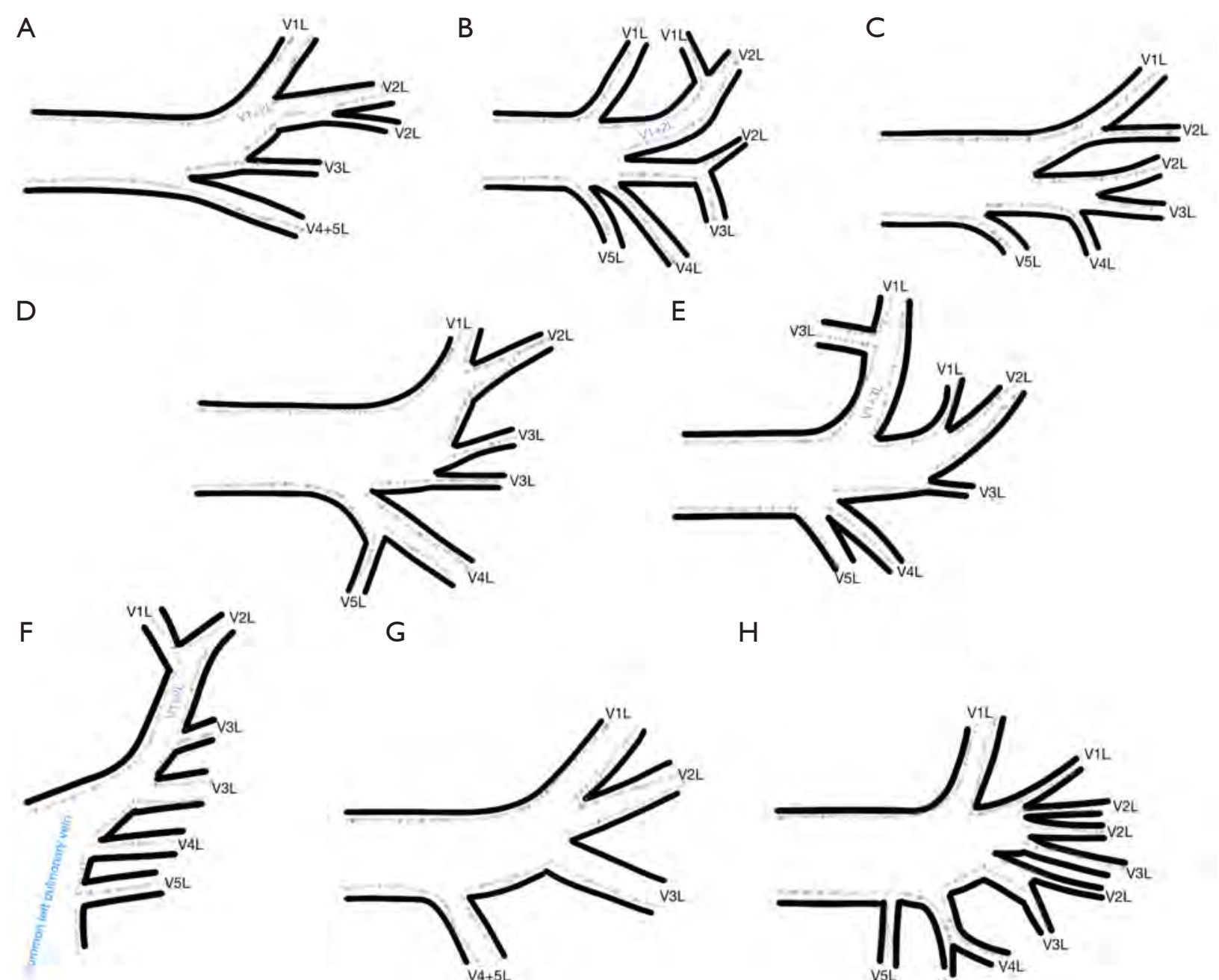

G

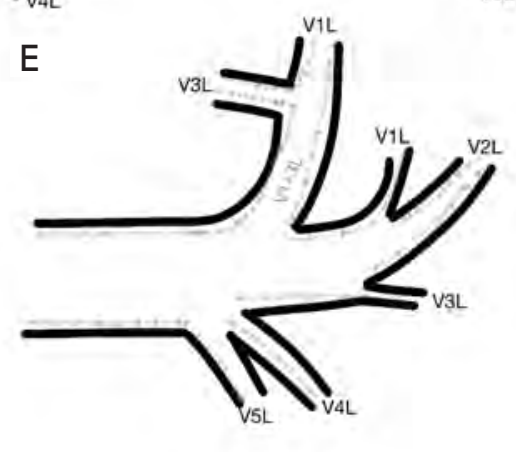

$\mathrm{H}$
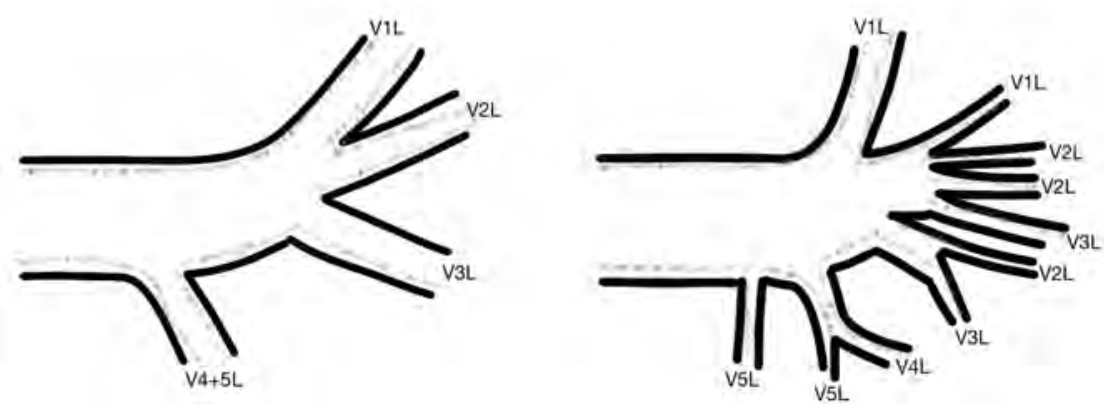

Figure S5 Most common segmental veins of the left upper lobe. 


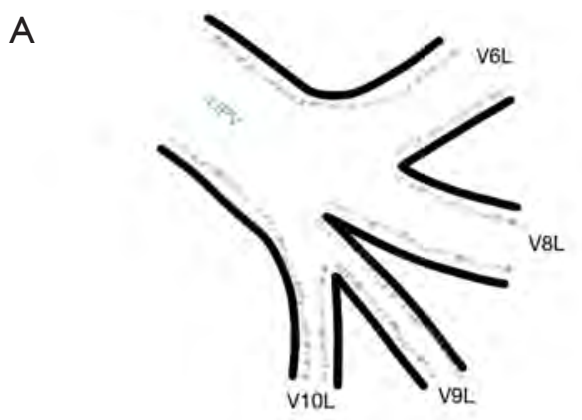

B
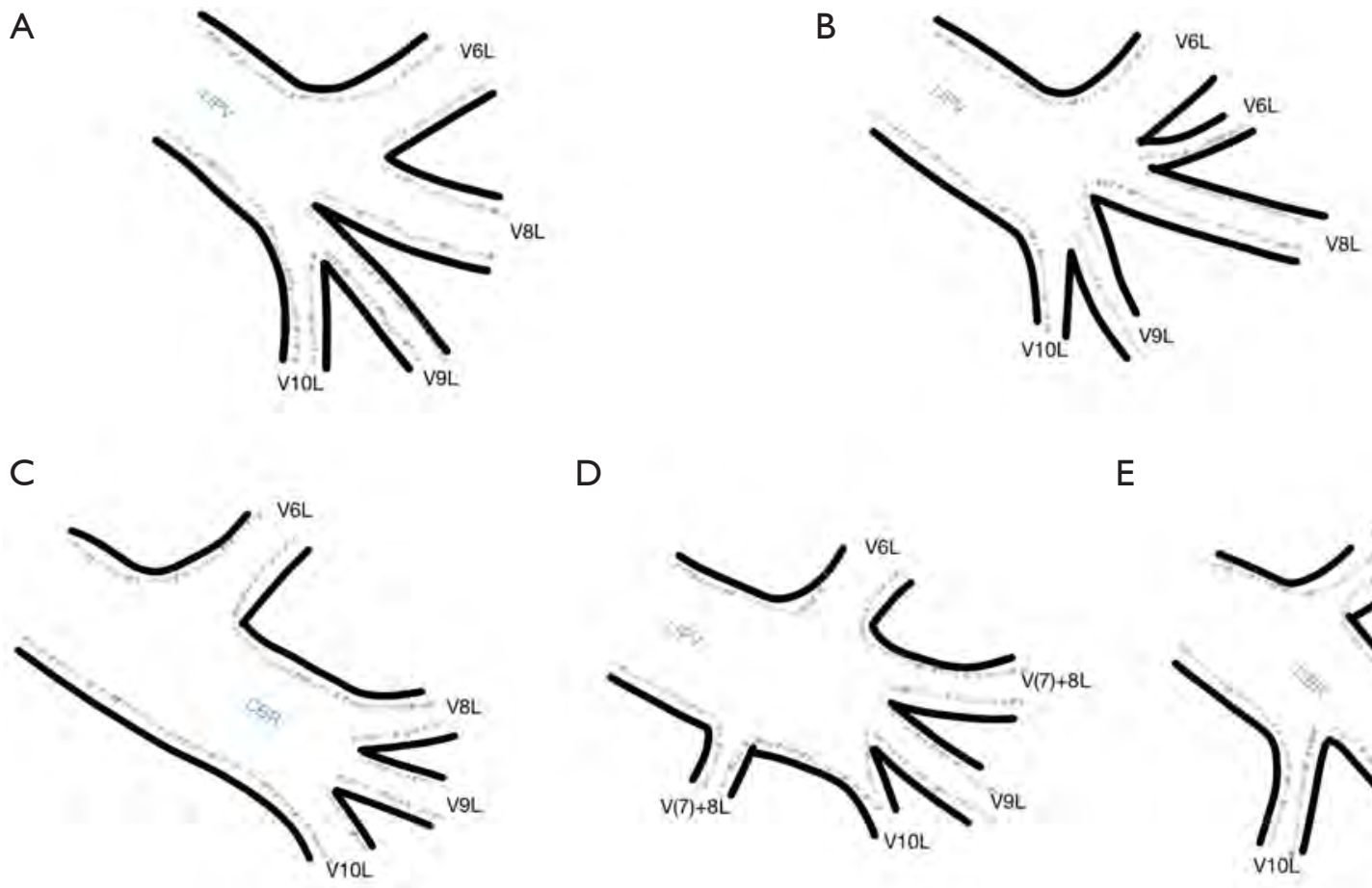

D

E
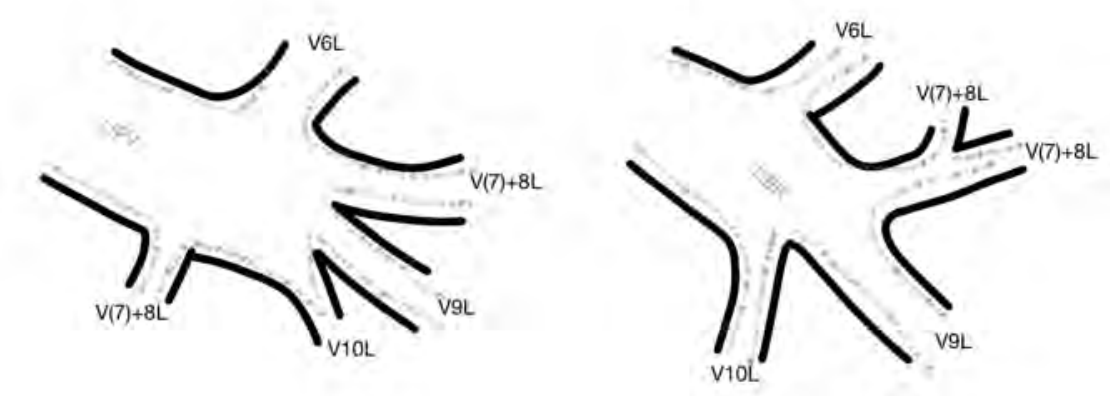

Figure S6 Most common segmental veins of the left lower lobe. CBR, common basal root; LIPV, left inferior pulmonary vein. 

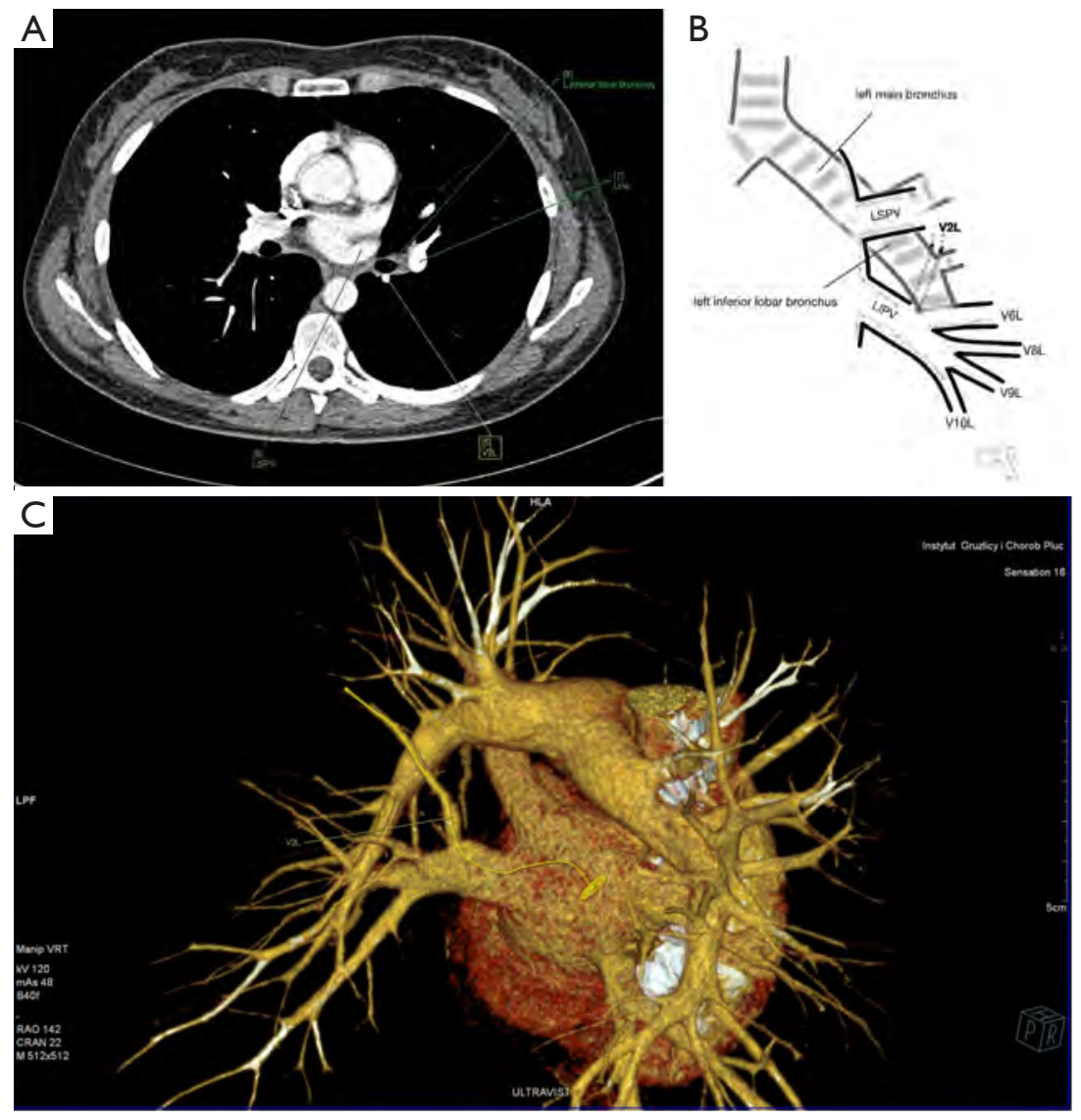

Figure S7 Retrobronchial course of the vein of the posterior segment of the left upper lobe (V2L) with outflow to the left inferior pulmonary vein (LIPV) close to V6L. (A) CT, axial plane, mediastinal window; (B) schematic anterior view; (C) CT with VRT, right posterior oblique view. CT, computed tomography; VRT, volume rendering technique. 

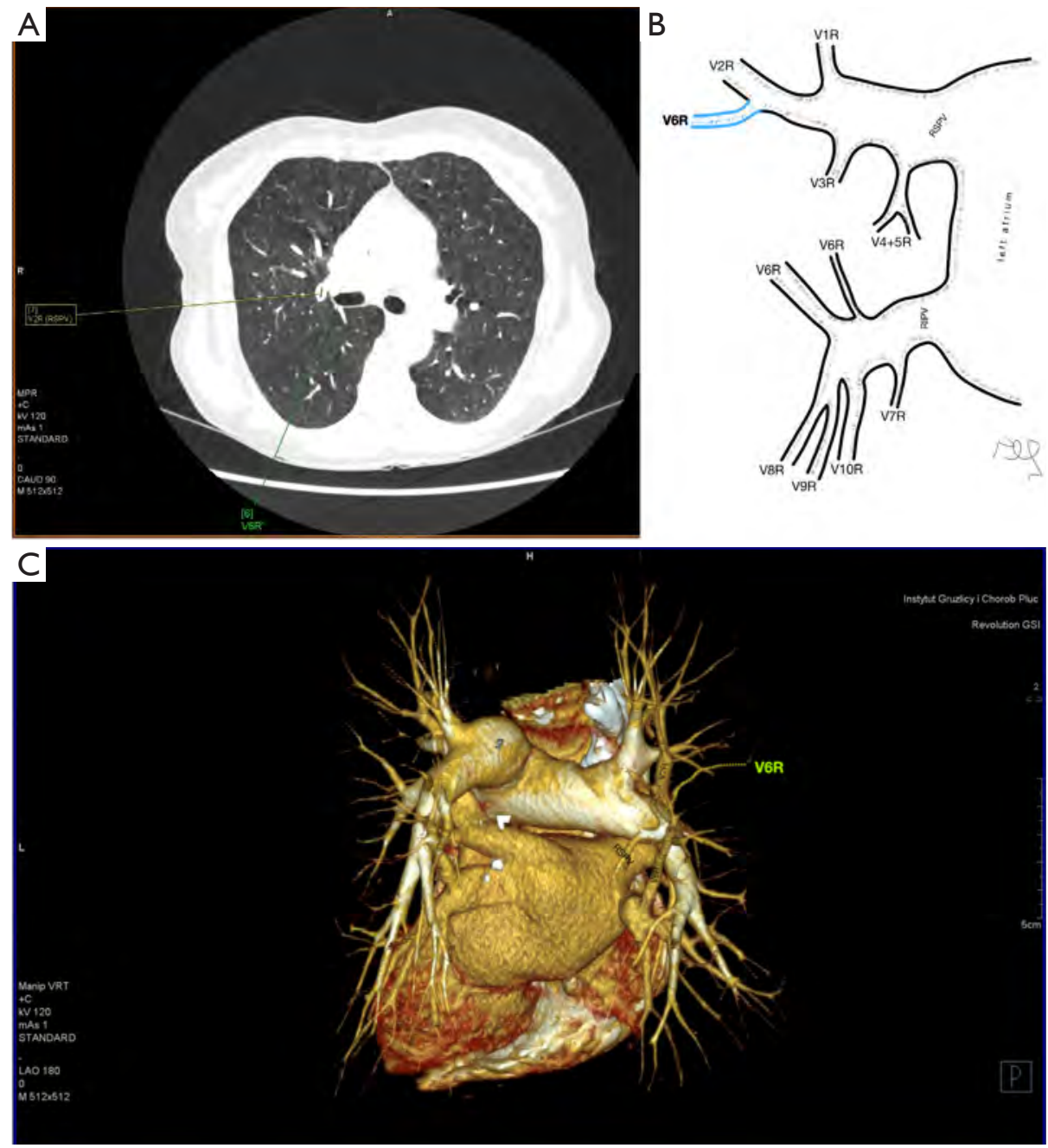

Figure S8 Accessory vein of the apical segment of the right lower lobe (V6R) connects with the vein of the posterior segment of the right upper lobe (V2R). (A) CT, axial plane, lung window; (B) schematic anterior view; (C) CT with VRT, posterior view. CT, computed tomography; VRT, volume rendering technique. 

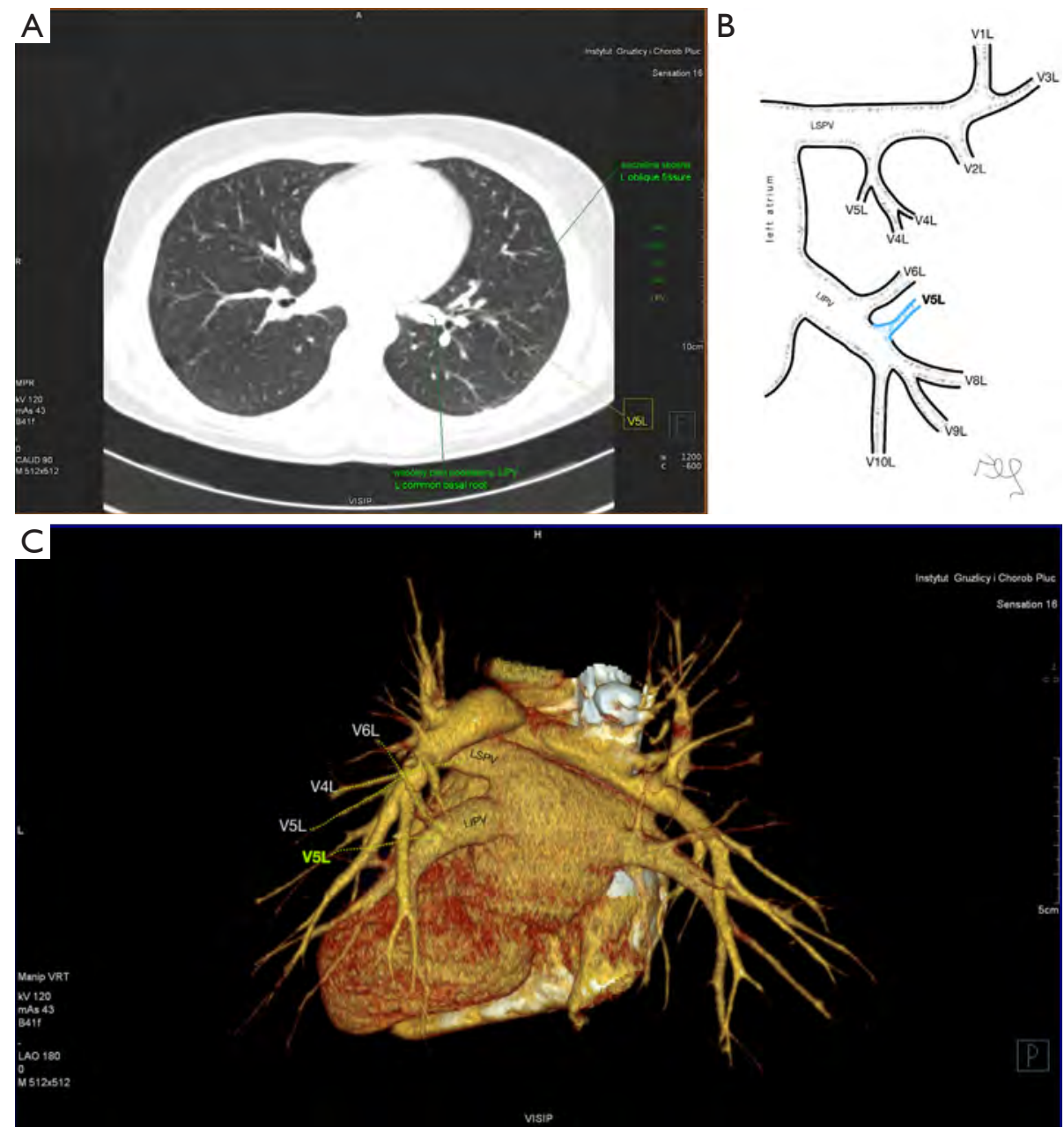

Figure S9 Partial outflow from the lingua of the upper left lobe to the left inferior pulmonary vein (LIPV): the vein of the inferior lingual segment (V5L) drains into LIPV. (A) CT, axial plane, lung window; (B) schematic anterior view; (C) CT with VRT, posterior view. CT, computed tomography; VRT, volume rendering technique. 